\title{
Feto-maternal haemorrhage: a review after and a case report
}

\author{
Ruchi Bhandari*, Manju Khemani, Asif Mustafa
}

Department of Obstetrics and Gynecology, Max Smart Super Speciality Hospital, Saket, New Delhi, India

Received: 06 March 2019

Accepted: 08 April 2019

\section{*Correspondence:}

Dr. Ruchi Bhandari,

E-mail: ruchi.bhandari@yahoo.com

Copyright: ( $)$ the author(s), publisher and licensee Medip Academy. This is an open-access article distributed under the terms of the Creative Commons Attribution Non-Commercial License, which permits unrestricted non-commercial use, distribution, and reproduction in any medium, provided the original work is properly cited.

\section{ABSTRACT}

Feto-maternal haemorrhage is the transmission of fetal blood cells to the maternal blood stream. It is quite common in small volumes- occurring in most pregnancies. Large volumes of feto-maternal haemorrhage can have serious consequences. Some risk factors are identified, but they are not always present. Decreased perception of fetal movements is most important clinical sign, together with a pathological NST. Prompt diagnosis and immediate obstetric care is fundamental, as serious risk to the fetus might result from this condition. Author described the case report of 35 years old G3P1L1A1 with 37 weeks 5 days pregnancy, who came in outpatient department with reduced perception of fetal movements during the previous 10 hours. There was no history of abdominal trauma. Cardiotocograph showed nonreactive NST with minimal beat to beat variability for more than 40minutes. An emergency caesarean section was performed and a female limp baby delivered with heart rate $<60 /$ minutes, pale, no respiration and no reflexes. Baby resuscitated with bag and tube ventilated. APGAR score was 3/5/6 at 0, 1 , and 5 minutes. Fetal haemoglobin at the first hour of life was $3.0 \mathrm{gm} / \mathrm{dl}$. Kleihauer-Betke test revealed $265.7 \mathrm{ml}$ of fetal erythrocytes in the maternal blood stream. Despite being rare, it is important to detect a massive feto-maternal haemorrhage. Fetal anemia could be suspected, but the diagnosis was only made after delivery. This case reveals the importance of keeping a high suspicion in obstetric practice, as feto-maternal haemorrhage is a rare but potentially catastrophic event for a fetus.

Keywords: Fetal-maternal haemorrhage, Fetal anemia, Kleihauer-Betke test, NST

\section{INTRODUCTION}

Fetal-maternal haemorrhage $(\mathrm{FMH})$ consists of the transmission of fetal blood cells into the maternal circulation. Although, the pathophysiology is not yet completely understood. It is likely to occur in small volumes in all pregnancies, with no apparent clinical significance in most cases. The incidence of clinically significant feto-maternal haemorrhage varies widely. Many studies defined $30 \mathrm{ml}$ as threshold for meaningful fetal blood volume and $80 \mathrm{ml}$ or $150 \mathrm{ml}$ as cut off of large or massive feto-maternal bleeds. Massive feto-maternal haemorrhage is more likely to be fatal if blood loss occurs over minutes rather than hours.
The blood pressure is higher in placental blood vessels than in the intervillous space. If the maternal-fetal barrier is disrupted, haemorrhage occurs from fetal to the maternal circulation. Incidence increases with gestational age and same for the volume of fetal blood loss in the maternal circulation. Presenting symptoms are nonspecific, with the most common being decreased fetal movements. Feto-maternal haemorrhage has been associated with risk factors like number of placental disorders (e.g. Chorioangioma, abruption, monochorionic-monoamniotic twins and pre- eclampsia) and external forces acting on the mother or uterus (e.g. Trauma, external cephalic version, invasive procedures 
like amniocentesis or manual removal of placenta). However no cause was identified in over $80 \%$ of cases.

Recognizing the feto-maternal bleed before it becomes significant requires a high index of suspicion as the triad of decreased fetal movements, sinusoidal heart rate, and hydrops fetalis corresponds to a group of symptoms of severe anemia associated with massive feto-maternal haemorrhage. In some situations, such as unexplained stillbirth, persistent fetal perception of decreased fetal movement activity, hydrops and unexplained elevated middle cerebral artery doppler, testing for feto-maternal haemorrhage should be considered. Amongst the different diagnostic tests available, the Kleihauer-Betke is a quantitative test based on the principle that haemoglobin $\mathrm{F}(\mathrm{Hb} \mathrm{F})$ is relatively resistant to acid elution compared with the haemoglobin of adult erythrocytes.

When a massive fetal haemorrhage occurs it is crucial to promptly detect it. Immediate delivery is recommended if the fetus is near term gestation. In cases of preterm gestation, in utero transfusion can be considered to minimize the side effects of fetal anemia. If untreated, the effects of feto-maternal haemorrhage can be catastrophic, potentially resulting in cardiac failure, hydrops, hypovolemic shock, intrauterine demise, neonatal death, neurological injury, cerebral palsy or persistent pulmonary hypertension.

\section{CASE REPORT}

A 35 years old booked third gravida with previous one caesarean for CPD and one abortion with $37+5$ weeks pregnancy came in our emergency department with complaints of decreased fetal movements for approximately 8-10 hours. Her menstrual cycles were regular and with no significant past history of any medical or surgical illness. Her quadruple marker was in high risk for Trisomy 21 thus amniocentesis was done at 18-19 weeks of pregnancy which was reported normal. She was AB positive, and all her all antenatal ultrasounds and blood test were normal. She developed cholestasis in late third trimester of pregnancy for which she was given ursodeoxycholic acid and no other problems in antenatal period. Patient was admitted and on CTG it was nonreactive NST with minimal beat to beat variability for $>40 \mathrm{~min}$ inspite of given IV fluids, intranasal oxygen and left lateral position. There was no history of abdominal trauma and blood pressure was normal. There was no history of pain abdomen or blood stained discharge.

It was decided to do emergency caesarean section in view of prolong decreased feta movements, nonreactive NST, and minimal beat to beat variability (Figure 1 and 2) for prolong period of time.

A female infant was born of $2600 \mathrm{gm}$ with an APGAR of 3,5 and 6. Fetal haemoglobin at the first hour of birth was $3.0 \mathrm{gm} / \mathrm{dl}$. Maternal workup included hemogram, biochemistry panel and coagulation profile. Her infection screening and basic blood investigations were already available and Kleihauer-Betke test send. Notably, Kleihauer-Betke test revealed $265.7 \mathrm{ml}$ of fetal erythrocytes in maternal blood.

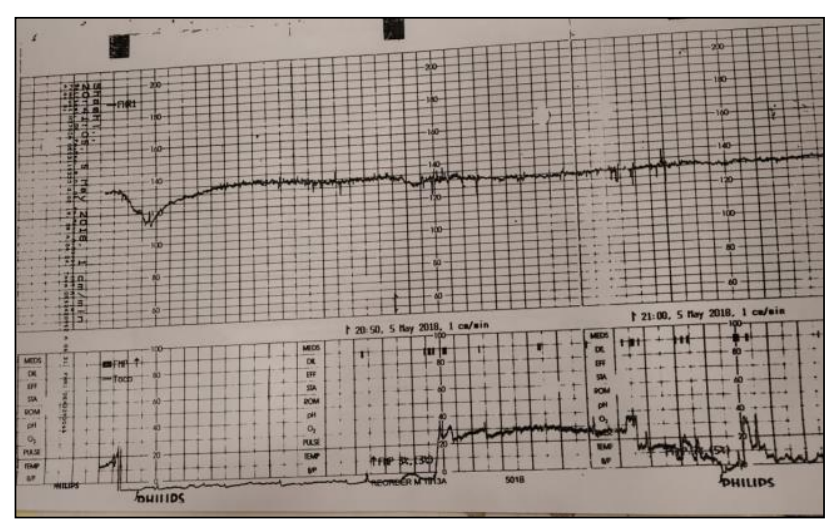

Figure 1: Decrease beat to beat variability on admission.

Fetus after putting on ventilatory support had HR130/min and RR-60/min with spo2-94\% on FIO2 80\% with no gross congenital anomaly. Fetus was given PRBC and FFP. On $5^{\text {th }}$ day the haemoglobin of infant was $13.2 \mathrm{gm} / \mathrm{dl}$ with normal thyroid profile, complete blood counts and liver and kidney function test. All investigations and direct coomb's test were negative. She was discharged on $9^{\text {th }}$ postoperative day from the hospital.

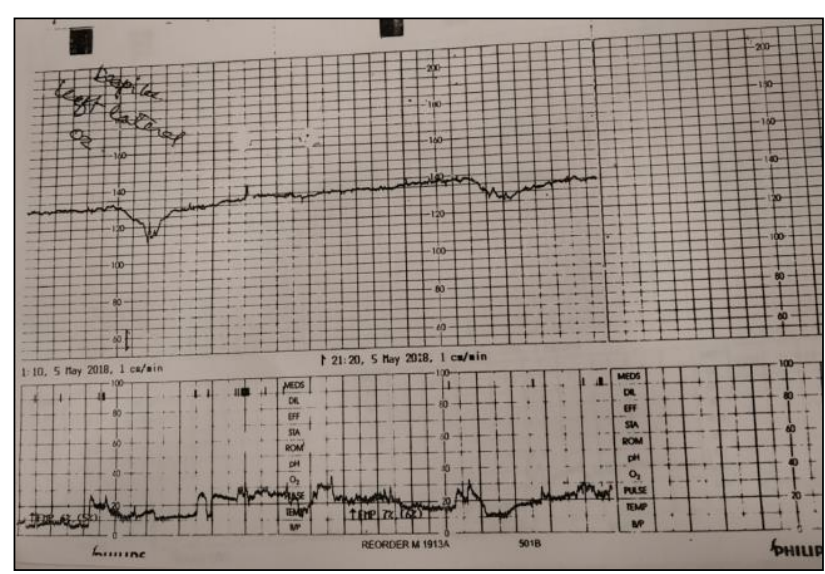

Figure 2: Minimal beat to beat variability after iv fluids, left lateral position and oxygen inhalation after 30min with deccelerations.

\section{DISCUSSION}

Feto-maternal haemorrhage was first established as a clinical entity during the 1940's and 1950's., ${ }^{1,2}$ Spontaneous feto-maternal haemorrhage $(\mathrm{FMH})$ is defined as feto-maternal bleeding with no antecedent history of trauma and no clinical/histo-pathological evidence of abruption. The vast majority of spontaneous 
FMHs are small volume bleeds of no hemodynamic significance, but they may lead to alloimmunization. The frequency and volume of these types of bleeds increase with advancing gestational age and are highest at delivery. ${ }^{3}$

Spontaneous massive (also called large) feto-maternal haemorrhage (FMH) is much less common. If acute, it can result in rapid fetal hemodynamic collapse and death. If chronic (i.e. intermittent repetitive FMH), it can result in fetal anemia and hydrops fetalis, depending on the ability of fetus to increase red cell production and compensate for ongoing blood loss.

Massive FMH greater than $30 \mathrm{ml}$ occurs in only about 3 of 1000 pregnancies. The volume of blood loss required to affect the fetus is variable and is related to the cause and whether the loss is acute or chronic. It has not been shown to directly correlate with perinatal morbidity or mortality.

Many studies demonstrate that the initial and most significant warning sign for FMH is the mother's report of reduction in fetal movement. As mentioned earlier, although various risk factors are identified, most cases occur without any identifiable cause. For this reason it is vital to be aware of FMH even when no risk factors are found. Women should be advised to pay attention to fetal movements and to seek for medical care after any trauma.

FMH can follow maternal abdominal trauma., Haemorrhages have occurred following maternal falls and motor vehicle accidents. ${ }^{6}$ It has also been linked to various obstetric procedures such as external cephalic version, manual removal of retained placenta, or amniocentesis. ${ }^{6-10}$ Placental anomalies such as tumour or chorioangioma, abruption, and monochorionicmonoamnionic twins have also been identified as cause of abruption. ${ }^{6,11-14}$ However, $82 \%$ of cases arise spontaneously, with no identifiable history of an inciting event. $^{15}$

The initial symptoms of an acute FMH are often subtle and nonspecific. Most are diagnosed retrospectively after an infant is stillborn, experiences unexplained fetal distress or is born with symptoms consistent with a haemorrhage. ${ }^{16}$ Prenatally mother may present with a history of decreased or absent fetal movement. ${ }^{17}$ Fetal heart rate monitoring may show a sinusoidal pattern, a lack of acceleration, and recurrent late deceleration. ${ }^{18,19}$ If the fetus can compensate for the blood loss, the pregnancy may continue to delivery of infant with varying degrees of anemia. Initially the fetus may increase cardiac output, with fetal tachycardia reported as presenting symptom, that can be measured on doppler ultrasound studies. ${ }^{20}$ Sueters correlated increased flow in the fetal middle cerebral artery with anemia. ${ }^{21}$

In the setting of uncompensated anemia, the fetus may develop high output heart failure and hydrops fetalis due to changes in the hydrostatic (oncotic) pressure. ${ }^{22}$ The triad of decreased fetal movement, sinusoidal heart rate, and hydrops fetalis are symptoms of severe anemia associated with massive FMH. However this combination is late presentation of disease. ${ }^{17}$

One should consider FMH as part of the differential diagnosis for fetal or immediate neonatal anemia. We describe a unique case of FMH that demonstrated acute clinical features. It is our hope that this case will assist practitioners in differentiating acute FMH that may require emergent delivery from chronic FMH which may be able to be expectantly managed.

\section{CONCLUSION}

Feto-maternal haemorrhage is a rare, potentially catastrophic event for a fetus. Leakage of the fetus blood into the mother's circulation can cause fetal anemia, hydrops, and even death. The prevailing symptom is decreased fetal movement, and signs can include a sinusoidal electronic fetal monitor pattern, a positive Kleihauer-Betke test, or changes in fetal Doppler blood flow. A mother's report of perception of decreased fetal movement coupled with a nonreactive non-stress test or abnormal ultrasound findings should prompt an investigation into underlying causes.

\section{Recommendations}

If ongoing and rapid haemorrhage is occurring then immediate delivery of the foetus may be indicated if the fetus is sufficiently developed. If the haemorrhage has already occurred and now stopped, an in-utero transfusion of red cells to the foetus may be recommended.

Funding: No funding sources

Conflict of interest: None declared

Ethical approval: Not required

\section{REFERENCES}

1. Weiner AS. Diagnosis and treatment of anemia of the new born caused by occult placental haemorrhage. Am J Obstet Gynecol. 1948;56(4):71722.

2. Chown B. Anemia from bleeding of the fetus into the maternal circulation. Lancet. 1954;266(6824):12135.

3. Dana M, Fibach E. Fetal hemoglobin in the maternal circulation - contribution of fetal red blood cells. Hemoglobin. 2018;42:138.

4. Blickers RG, Wennberg R. Fetomaternal transfusion following trauma. Am J Obstet Gynecol. 1983;61(2):258-9.

5. Rose PG, Strohm PL, Zuspan FP. Fetomaternal haemorrhage following trauma. Am J Obstet Gynecol. 1985;153(8):844-7. 
6. Renaer M, de putte I Van, Vermylen C. Massive feto-maternal haemorrhage as a cause of perinatal morbidity and mortality. Eur J Obstet Gynecol Reprod Biol. 1976;6(3):125-40.

7. Nord E, Blaschke E, Green K, Thomassen P. 100 cases of external cephalic version, with special reference to fetomaternal transfusion. Acta Obstet Gynecol Scand. 1989;68(1):55-8.

8. Queenan JT, Nakamoto M. Postmortem immunization: the hypothetical hazard of manual removal of placenta. Obstet Gynecol. 1964;23:392-5.

9. Queenan JT, Adams DW. Amniocentesis: A possible immunizing hazard. Obstet Gynecol. 1964;24:530-2.

10. Bowman JM, Pollock JM. Transplacental haemorrhage after amniocentesis. Obstet Gynecol. 1985;66(6):749-54.

11. Sims DG, Barron SL, Wadehra V, Ellis HA. Massive chronic feto maternal bleeding associated with placental chorioangiomas. Acta Paediatcr Scand. 1976;65(2):271-3.

12. Santamaria M, Benirschke K, Carpenter PM, Baldwin VJ, Pritchard JA. Transplacental haemorrhage associated with placental neoplasms. Pediatr Pathol. 1987;7(5-6):601-5.

13. Cardwell MS. Ultrasound diagnosis of abruptio placentae with fetomaternalhaemorrhage. Am J Obstet Gynecol. 1987;157(2):358-9.

14. Verco CJ, Jones WR. Monoamniotic twin pregnancy complicated by massive fetomaternal haemorrhage. Aust N Z J Obstet Gyneacol. 1981;21(3):186-7.

15. Giacoia GP. Severe fetomaternal haemorrhage: a review. Obstet Gynecol Surv. 1997;52(6):372-80.

16. Eliegner JRH, Fortune DW, Barrie JU. Occult fetomaternal haemorrhage as a cause of fetal mortality and morbidity. Aust N Z J Obstet Gynaecol. 1987;27(2):158-61.

17. De Almeida V, Bowman J M. Massive fetomaternal haemorrhage: Manitoba experience. Obstet Gynecol. 1994;83(3):323-8.

18. Modanlou HD, Freeman RK. Sinosoidal fetal heart rate pattern: Its definition and clinical significance. Am J Obstet Gynecol. 1982;142(8):1033-103.

19. Moise KJ. Diagnosis and management of massive fetomaternal haemorrhage. Uptodate available at: http:/www.uptodate.com/contents/diagnosis-andmanagement-of-massive-fetomaternal-hemorrhage. Accessed July, 2011.

20. Jump UP, Sebring ES, Polesky HF. Fetomaternal Hemorrhage: Incidence, risk factors, time of occurrence, and clinical effects". Transfusion. 1990;30:344-57.

21. Nicolaides KH, Sadovsky G, Visser GH. Heart rate patterns in normoxemic, hypoxemic, and anemic second trimester foetuses. Am J Obstet Gynecol. 1989;160(5pt 1):1034-7.

22. Sueters M, Arabin B, Oepkes D. Doppler sonography for predicting fetalanemia caused by massive fetomaternal haemorrhage. Ultrasound Obstet Gynecol. 2003;22(2):186-9.

Cite this article as: Bhandari $\mathrm{R}$, Khemani $\mathrm{M}$, Mustafa A. Feto-maternal haemorrhage: a review after and a case report. Int J Reprod Contracept Obstet Gynecol 2019;8:2142-5. 